\title{
0 registro das Diretivas Antecipadas de Vontade: opinião dos tabeliães da cidade de Porto Alegre - RS
}

The record of Advance Directive of Will: opinion of notaries of Porto Alegre city/RS

\author{
Anelise Crippa* \\ Anamaria Gonçalves dos Santos Feijón *
}

\begin{abstract}
Resumo
A Diretiva Antecipada de Vontade diz respeito à manifestação de vontade de forma antecipada, em relação aos cuidados e tratamentos para momentos em que a pessoa está incapacitada de se manifestar. O objetivo deste estudo foi verificar como estavam ocorrendo estas manifestações em tabelionatos e se os notários estavam cientes do seu conteúdo, abrangência e necessidades da sociedade em registrá-la. Formulou-se um questionário para entrevista semiestruturada, em uma pesquisa qualitativa, para verificar como estão ocorrendo estes procedimentos nos tabelionatos de Porto Alegre/RS. Foram entrevistados os 12 responsáveis pelos respectivos tabelionatos que manifestaram, na sua maioria $(66,7 \%)$, conhecer as Diretivas Antecipadas de Vontade, mas pouco registrá-las (registros inferiores à 3 por tabelionato). Verificou-se, portanto, que apesar das DAV terem emergido do anseio da sociedade, ainda é pouca a procura nos tabelionatos. Ressaltou-se que, embora não haja obrigatoriedade deste registro, nem lei que imponha esta necessidade aos tabeliães, há segurança jurídica atribuída aos atos firmados perante notário, o que deveria configurar uma maior procura por parte dos interessados, nos órgãos competentes.
\end{abstract}

Palavras-chave: Bioética. Diretivas Antecipadas. Testamentos quanto à vida. Autonomia Pessoal.

\begin{abstract}
The Advance Directive of Will (ADW), concerns the manifestation of will in advance in relation to care and treatment during times when the person is unable to manifest themselves. The aim of this study was to determine how these events were occurring in notary public offices, if the notaries were aware of its content, comprehensiveness and the needs of society to put it on record. A questionnaire was formulated for a semi-structured interview, part of a qualitative study, to verify how procedures are being executed at notary public offices in Porto Alegre/ RS. Twelve people responsible for notary public offices were interviewed, the majority $(66,7 \%)$ of whom knew about the Advance Directive of Will (ADW); however, a low number of registrations occurred (less than three registrations per notary public office). It can be highlighted that, despite the fact that ADWs were created in response to needs posed by society, this instrument is little used. It was highlighted that, although registration is not mandatory and that there is not a law which imposes this need on notary public officials, there is a legal security aspect attributed to acts signed before notary public officials, which should promote a higher demand by the interested parties at competent organs.
\end{abstract}

Keywords: Bioethics. Advance Directives. Living Wills. Personal Autonomy

DOI: 10.15343/0104-7809.20164002257266

\footnotetext{
* Faculdade Cenecista de Osório - FACOS. Osório - RS, Brasil. E-mail: anecrippa@gmail.com

** Unidade de Pesquisa Clínica Carlos Isaia Filho. Porto Alegre - RS, Brasil

As autoras declaram não haver conflitos de interesse.
} 


\section{INTRODUÇÃO}

Nas últimas décadas vem ocorrendo um prolongamento da expectativa de vida em nosso país. ${ }^{1} \mathrm{O}$ expressivo crescimento da população idosa brasileira vem sendo comprovada a cada censo, sendo evidenciado que de 1999 para 2009 a composição da população passou de $9,1 \%$ de idosos para 11,3\%. ${ }^{2}$ Dos Estados brasileiros, é no Rio Grande do Sul que está a maioria da população idosa, correspondendo a $13,8 \%$, seguido do Rio de Janeiro com $13,1 \%{ }^{2}$

Embora muito já se tenha falado em aumento do tempo de existência sem qualidade de vida, hoje tem-se um cuidado maior com a saúde e a preocupação com a forma e estilo de vida. As informações sobre qualidade de vida já vêm sendo usadas como indicadores para avaliação da eficácia, eficiência e impacto de certos tratamentos para grupos diversos e vem influenciando decisões e condutas terapêuticas das equipes de saúde. Esta compreensão ampliada da qualidade de vida preconizada pela OMS abrange também as esferas sociais ocasionando mudanças até culturais, e também pode-se manifestar na forma como as pessoas desejam vivenciar seus últimos instantes. ${ }^{3}$

Baseada na proteção da autonomia do indivíduo, a Câmara Técnica de Bioética do Conselho Federal de Medicina redigiu e publicou em 31 de agosto de 2012, a Resolução 1.995 que dispõe sobre as Diretivas Antecipadas de Vontade. Esta Resolução apresenta para a população brasileira, a possibilidade de que haja uma manifestação de vontade prévia a um ato de saúde e que se possa deixar expresso a ação que considera acertada, respeitando os preceitos éticos do Código de Ética Médica brasileiro, independendo da vontade de seus familiares. ${ }^{3}$

Define assim, a referida Resolução, no seu artigo 1, Diretivas Antecipadas de Vontade como "o conjunto de desejos, prévia e expressamente manifestados pelo paciente, sobre cuidados e tratamentos que quer, ou não, receber no momento em que estiver incapacitado de expressar, livre e autonomamente, sua vontade". ${ }^{4}$

Quando o paciente não puder manifestar sua decisão em relação aos cuidados e tratamentos, o médico considerará suas Diretivas Antecipadas de Vontade para procedimentos mesmo estando os familiares do enfermo em desacordo com essas Diretivas. Se houver um representante legal, este será consultado. No entanto, caso a vontade do enfermo esteja em desacordo com os preceitos éticos da medicina, o médico não considerará a vontade do paciente. ${ }^{4}$

Nos casos em que haja um representante, como expõe Alves, este poderá verificar se surgiram novos tratamentos que possam beneficiar o paciente, tendo em vista os avanços da medicina. Este equilíbrio entre o respeito à autonomia e à beneficência, como esclarece a autora, liga elementos bioéticos e jurídicos para análise de cada caso, buscando um adequado tratamento ao paciente. ${ }^{5}$

Ao terem conhecimento das Diretivas Antecipadas de Vontade, os médicos registrarão no prontuário o desejo do paciente. ${ }^{4}$ Será com o cumprimento desta diretiva que o paciente terá respeitada a sua autonomia de vontade. A ação proferida pelos médicos tem grande peso, pois eles cumprirão ou não efetivamente a vontade do paciente. A Diretiva Antecipada de Vontade se mostra de suma importância para a classe médica porque é um instrumento regulamentador específico para esta categoria, haja vista que não temos uma normatização sobre este fato, apenas a supramencionada Resolução. ${ }^{6}$

Nos casos em que são desconhecidas as Diretivas Antecipadas de Vontade do paciente e não havendo familiar disponível ou ainda, estando os familiares em desacordo entre si, o médico se reportará ao Comitê de Bioética da instituição, caso exista, ou, na falta deste, à Comissão de Ética Médica do hospital ou ainda ao Conselho Regional e Federal de Medicina para fundamentar sua decisão sobre conflitos éticos, quando entender esta medida necessária e conveniente. ${ }^{4}$

Não há regramento para o momento adequado de efetuar a Diretiva, porém, há quem sustente que seria mais adequado apenas registrá-la após o conhecimento de uma doença, havendo uma reflexão entre paciente, familiares e equipe médica. ${ }^{7}$ No entanto, aguardar a ocorrência de um incidente de saúde para posteriormente registrar sua vontade mostra-se 
temeroso, pois com as fatalidades e imprevistos da vida nem sempre será possível aguardar esse momento, como por exemplo, casos de AVC, derrame, isquemia, dentre outras.

Diante dessa possibilidade de manifestação, as autoras questionam-se sobre qual a forma mais adequada e segura, capaz de proteger a autonomia de vontade do indivíduo, para assegurar a sua vontade. Sendo assim, a formalização desse documento em tabelionato atribuiria mais segurança a sua vontade. Porém, não ficou especificado na Resolução 1.995/2012 que essa deva ser a forma atribuída às Diretivas Antecipadas de Vontade, haja vista que o Conselho Federal de Medicina tem competência apenas em relação aos médicos, por ser um órgão de classe, capaz de criar resoluções para estes, mas não tem competência legislativa para formular leis.

Salienta Lippmann que a formalização desta Diretiva no tabelionato não é necessária, como visto acima, porém, para o referido autor, há vantagens em efetuar o registro, pois o documento se torna "de fácil acesso, podendo ser facilmente recuperado. " 7

No tabelionato temos como responsável o notário ou tabelião. Ele, munido de fé pública, exercerá a atividade de registro e poderá "formalizar juridicamente a vontade das partes". ${ }^{8}$ O notário e o tabelião tem a finalidade de "garantir ou dar eficácia a um negócio jurídico". ${ }^{9}$ Diante disso, tem-se que visualizar o tabelião ou notário como sendo um "documentador da vida social (...), pois presta um serviço fundamental à administração da justiça, pela fé pública que envolve seu labor, tanto em relação à eficácia probatória, como à força executiva, alcançando sua plenitude via sentença judicial". ${ }^{10}$ Além disso, também protege os direitos fundamentais, prevenindo litígios jurídicos, pois após a lavratura do documento público, este terá caráter probatório, ${ }^{11}$ ou seja, por ser um documento reconhecidamente legítimo pelo tabelião, forma-se como documento verídico da vontade da pessoa, sendo prova da real vontade da parte.

Segundo Ceneviva, a formalização jurídica do ato só poderá ocorrer quando o mesmo for redigido por profissional habilitado, para que, dessa forma, se conserve o desejo da parte e a veracidade da sua manifestação de vontade. ${ }^{12}$ Caso essa manifestação se dê por pessoa estrangeira, ela será redigida em língua portuguesa e, para ser reconhecida como verdadeira, necessitará estar presente um tradutor público juramentado, o qual assinará o ato conjuntamente.

Ressalta-se que, como responsável, "os notários e oficiais de registro responderão pelos danos que eles e seus prepostos causem a terceiros, na prática de atos próprios da serventia, assegurado aos primeiros direitos de regresso no caso de dolo ou culpa dos prepostos".$^{8}$ O registro de maneira incorreta ou se valendo de má-fé pode responsabilizá-los civil e até penalmente.

Desse modo, nota-se a valoração dada aos tabeliães, sendo de suma importância analisar suas condutas no que toca as Diretivas Antecipadas de Vontade, a fim de averiguar se estes serventuários possuem o real entendimento acerca dessa forma de fazer valer a vontade daqueles que o procuram e como esta declaração vem sendo feita.

\section{MÉTODO}

A presente investigação trata-se de uma pesquisa exploratória-descritiva, de natureza qualitativa, na qual foram entrevistados todos os tabeliães/subtabeliães da cidade de Porto Alegre-Rio Grande do Sul. Esta investigação teve aprovação do Comitê de Ética em Pesquisa da Pontifícia Universidade Católica do Rio Grande do Sul, sob o no 358.730. Todos os participantes assinaram um Termo de Consentimento Livre e Esclarecido em duas vias, antes do início da entrevista.

Foi elaborado um questionário semiestruturado, o qual possui 10 questões norteadoras, versando sobre a Resolução 1.995/2012 que trata das Diretivas Antecipadas de Vontade. Como critério de inclusão a pessoa deveria ser tabelião, tabelião substituto ou sub-tabelião quando o tabelião não estivesse presente no tabelionato, e este estivesse à frente do cartório. Na cidade de Porto Alegre há 12 tabeliães, sendo que todos foram convidados 
a participar da pesquisa e aceitaram o convite. Foi feito um contato prévio pessoalmente para convidar os tabeliães a participar da pesquisa e, nesta ocasião, Ihes foi explicado, o teor da investigação e solicitado um horário com os notários para realização da pesquisa.

A entrevista ocorreu de forma individual, em cada um dos 12 tabelionatos, no período de agosto de 2013 a maio de 2014, sendo todas gravadas e, posteriormente, degravadas. Para sigilo das identidades dos entrevistados, foram utilizados nomes de flores, usual na pesquisa qualitativa, aqui dispostos em ordem alfabética, para não identificar a numeração correspondente a cada tabelionato: Bromélia, Cravo, Crisântemo, Gérbera, Girassol, Hortência, Jasmim, Lírio, Orquídea, Rosa, Tulipa, Violeta. Não foram utilizadas letras alfabéticas para não haver a possibilidade de ocorrer correspondência entre a letra e o tabelionato - primeira letra A corresponder ao primeiro tabelionato e, assim, sucessivamente. Os nomes das flors foram escolhidos de forma aleatória e, aqui, sua exposição em ordem alfabética impossibilitada a identificação entre os tabelionatos.

Para análise de frequência foi utilizado o software SPSS, versão 17.0 for Windows. Já as questões qualitativas, foram realizadas por análise de conteúdo, segundo Bardin. ${ }^{13}$

A análise de conteúdo ocorreu em três etapas: a) leitura das entrevistas buscando identificar uma visão coletiva dos tabeliães e o tema expresso em seus depoimentos; b) recorte dos trechos dos depoimentos, através de uma leitura horizontal, buscando localizar convergências e divergências das entrevistas; c) leitura vertical para identificar expressões, palavras e frases, que se identificavam entre os tabeliães, frente às diretivas antecipadas de vontade.

Ao final, buscou-se articular o material empírico com o referencial teórico, baseandose no objetivo proposto, buscando responder as questões norteadoras, do qual advieram as seguintes categorias: a) Conhecimento e opinião sobre a Resolução 1.995/2012; b) Critérios de avaliação da parte; c) Modelo para formalização da Diretiva Antecipada de Vontade d) Entrevista para avaliação da parte e) Atestado médico.

\section{RESULTADOS E DISCUSSÃO}

\section{Conhecimento e opinião}

As Diretivas Antecipadas de Vontade não precisam ser, obrigatoriedade, firmadas perante um tabelião. ${ }^{14}$ Isso decorre porque o Conselho Federal de Medicina, órgão de classe que, preocupado com a necessidade de adequar a conduta médica à questão da autonomia do paciente em situações de ordem ética ainda não prevista nos dispositivos éticos nacionais propôs a Resolução 1.995 a qual orienta apenas sobre a atuação do profissional da Medicina. Este dispositivo, que dispõe sobre as Diretivas Antecipadas de Vontade dos pacientes, não tem competência legislativa, apenas regulamenta os atos condizentes com a medicina não podendo nortear ações de outras profissões como ocorreria se o documento fosse oficializado por um instituto regulado por uma lei.

No entanto, a fé pública decorrente dos atos notariais configura uma segurança para a pessoa. Esta fé pública corresponde à confiança que a lei atribui para os atos que o tabelião faz ou declara, quando do exercício da sua função, designando veracidade. ${ }^{12}$ Tal atribuição e garantia de segurança jurídica vem com uma severa atribuição de regime de responsabilidade civil, administrativa e penal. ${ }^{15} \mathrm{E}$ é esta fé pública que dá segurança de veracidade da vontade de alguém quando se formaliza um documento no cartório, podendo ser uma declaração ou um instrumento público. Apesar de se mostrar como a forma mais concreta de comprovação da vontade para elidir possíveis conflitos, a certeza de que a sua vontade será cumprida pelo ato de ter sido feito em cartório, não há. Por exemplo, a única pessoa que tiver conhecimento deste registro pode não o informar à equipe médica e a vontade não ser cumprida, pois não temos um Registro Nacional único, que informe aos hospitais esse anseio. Porém, o registro desta vontade em cartório configura maior segurança ao declarante, no sentido de que podem ser levantadas pretensões diversas por parte de parentes, quando a pessoa não mais puder se manifestar, em relação à veracidade da declaração feita de próprio punho. 
Neste sentido está a função notarial, que tem seus atos revestidos de segurança jurídica, sendo este um intérprete do direito e não mero instrumentalizador e autenticador de documentos, que foi escolhido pelas partes por sua competência profissional. ${ }^{11} \mathrm{O}$ notário irá, portanto, manifestar a vontade da parte expressa na sua presença, conferindo-lhe veracidade. ${ }^{7} \mathrm{~A}$ realização deste registro com reconhecimento notarial também seria um benefício para a classe médica, pois ficariam mais resguardados em cumprir a vontade do paciente, sem possível questionamento dos familiares. Aos médicos, diante da limitação do alcance obrigacional de uma Resolução classista, ficou a incerteza de um processo ético, pois ao cumprir a vontade de seu paciente poderá ser questionado, tanto em processo administrativo, quanto jurídico, por familiares insatisfeitos e inconformados.

Para que ocorra o registro de uma Diretiva Antecipada de Vontade tanto a pessoa que deseja fazê-la, quanto os tabelionatos, precisam estar cientes da sua regulamentação e existência. Diante disso questionou-se aos tabeliães se eles conheciam a Resolução 1.995/2012, que versa sobre o referido tema. A maioria dos entrevistados $(66,7 \%)$ mencionou conhecer a regulamentação. Dos entrevistados 75\% acreditam que este instrumento é proveniente dos anseios da sociedade. No sentido da necessidade do vasto conhecimento do tabelião, dispõe Ana Amélia Marquezine Machado que, para exercer a função notarial, é necessário que o notário tenha amplo "conhecimento e perfeição técnica dos instrumentos jurídicos, bem como a forma de realização do direito. "16

Em se tratando da procura do tabelionato para registrar alguma direita antecipada de vontade, 58,3\% mencionaram saber que o tabelionato já havia feito este procedimento. Em nenhum dos tabelionatos em que foi realizada uma Diretiva Antecipada de Vontade ocorreram mais do que três registros. Mesmo os tabeliães que referiram desconhecer a Resolução 1.995/2012 adotam procedimentos legais para qualquer ato que irão registrar, realizando entrevistas e verificando a capacidade, conforme evidenciam os depoimentos:

"O tabelião tem três pilares sobre o ato jurídico que vai celebrar - tem que estar completo: agente capaz, objeto lícito, forma prescrita ou não prevista em lei"..."O dia que alguém aparecer, será idêntica a do testamento" (Gérbera)

"Teria que fazer uma análise caso a caso para saber até onde ele tem o direito de fazer e também até onde o tabelião vai ser solidário com essa situação" (Lírio)

"Qualquer dispositivo de vontade sofre, sofre não, passa por um processo de avaliação. " (Violeta)

"Para nós o único critério é a qualificação da pessoa e se ela está capaz ou não"..."A gente conversa com a parte e verifica a capacidade civil dela, como qualquer outro instrumento que a gente faça aqui" (Cravo)

Aos tabeliães que manifestaram conhecer as Diretivas Antecipadas de Vontade, foi perguntado qual a opinião que tinham sobre essa regulamentação. Todos se mostrarem favoráveis, conforme Tabela 1.

\section{Procedimento notarial}

Para a formalização de atos notariais, não raras vezes, há padrões já estabelecidos. O que se vê de exigências, de forma geral, são os requisitos estabelecidos pelo Código Civil, devendo a parte ser capaz, o objeto em questão ser lícito, determinável ou determinado, e a forma ser prescrita ou não defesa em lei. ${ }^{17}$

Com isso indagou-se se havia algum formulário padrão para a manifestação da vontade, sendo que a maioria $(66,7 \%)$ não adota nenhum modelo. Sendo feito por alguns como escritura declaratória (rosa, bromélia, gérbera), por instrumento público (cravo), e até mesmo dentro do testamento (orquídea). As manifestações quanto à existência de um modelo pré-determinado podem ser vistas na Tabela 2.

O testamento é um ato que só vem ao conhecimento público após o óbito da pessoa. Por isso, este não é o ato mais adequado, uma vez que é preciso que tenha o conhecimento para agir enquanto a pessoa está viva. Assim, sendo feito por uma declaratória, ele poderá ser retirado a qualquer momento no cartório. Assevera Paulo Lobo que de semelhança com o testamento, a diretiva de última vontade tem 
o fato de ser um ato de última vontade e, em diversidade, é de que sua finalidade versará durante a vida da pessoa e não, como o testamento, após sua morte. ${ }^{18}$

Ao que tange aos critérios exigidos pelos tabelionatos para proceder ao registro de uma diretiva, são utilizados os mesmos critérios legais de qualquer registro de documento notarial. É verificado se o agente é maior e capaz, se ele está ciente realmente do que quer e sabe as consequências daquele ato, se o pedido não irá contra algum dispositivo legal e se não está sendo coagido por alguém a realizar a diretiva. Os critérios estabelecidos pelo Código $\mathrm{Civil}^{17}$ no seu artigo 104, são os que nortearão as exigências dos tabeliães, para que o negócio jurídico se torne válido, ou seja, esses requisitos se aplicam para qualquer ato que uma pessoa realize em um tabelionato.

\section{Avaliação da parte}

A avaliação da capacidade da parte é um ponto crucial quando falamos de registrar sua vontade, e cabe ao próprio tabelião verificar esta capacidade uma vez que os critérios estabelecidos são subjetivos e não há critérios prévios para esta verificação. Para realizar esta ponderação, ocorre uma entrevista individual com a pessoa, na qual irá manifestar o que esta deseja registrar e porque está querendo este assentamento. Assim, o tabelião fará, através desta entrevista, uma análise da lucidez e da capacidade civil da pessoa, conforme pode-se verificar nas na fala dos tabeliães na Tabela. ${ }^{4}$

Em casos específicos, normalmente quando se refere a pessoas com idade avançada, ou há diligências fora no tabelionato, ou ainda, quando há possível dúvida da capacidade, alguns tabeliães usam da prudência e se cercam de um laudo médico. Esse pedido ocorre para a proteção da própria pessoa, pois com essa análise clínica há maior segurança caso haja questionamentos futuros quanto a capacidade da pessoa no momento em que firmou a Diretiva. Ressalta-se que esta não é uma exigência legal, nem está sendo adotada por todos notários, mas sim uma precaução que alguns optaram em adotar.

Caso algum dos critérios indispensáveis exigidos por lei não estejam presentes no ato, seria motivador para a recusa da formalização da Diretiva Antecipada de Vontade. Dos tabeliães que se manifestaram em recusar (58,3\%), por algum motivo, a redação de uma diretiva antecipada de vontade, verificam-se as seguintes justificativas:

"Tem que estar em perfeito juízo e claro entendimento, em uso e gozo pleno das suas faculdades intelectuais. Mentais eu não posso atestar, porque mentais eu não sou médico. " (Rosa)

"Dependendo do caso, pois é muito subjetivo. " (Lírio)

"Somente se tivesse alguma coisa contrária a lei. Porque a Diretiva de Vontade ela abre leques. " (Girassol)

"Aí depende do caso. Se é uma pessoa que visivelmente tem alguma deficiência, que tenha ou possa ser interditada, não estar na sua capacidade mental, aí sim. " (Cravo)

"Não só no caso de incapacidade, como a dificuldade de manifestar/expressar à vontade. " (Gérbera)

"Se eu sentisse que a pessoa não está lúcida o suficiente ou, a meu juízo, se está sendo coagida. " (Hortência)

Tabela 1 - Questionamento sobre qual a opinião dos tabeliães sobre as Diretivas Antecipadas de Vontade, realizado em Porto Alegre em 2014. (Categoria Conhecimento e opinião sobre a Resolução $1.995 / 2012)$

\begin{tabular}{ll}
\hline TABELIÃES & RESPOSTAS \\
\hline ROSA & $\begin{array}{l}\text { "Eu acho que pode ser feito, desde que não fira...venha de encontro ao permitido por lei ou } \\
\text { proibido por lei" ... "Eu concordo." }\end{array}$ \\
\hline BROMÉLIA & "Bueno, eu acho assim extremamente salutar, né?!" \\
\hline
\end{tabular}




\begin{tabular}{ll}
\hline JASMIM & $\begin{array}{l}\text { "Na verdade, eu concordo e, se acontecesse alguma coisa assim comigo, que chegasse a uma } \\
\text { doença em fase terminal, antecipadamente eu também faria. " }\end{array}$ \\
\hline GIRASSOL & $\begin{array}{l}\text { "Eu sou favorável, uma vez que para mim o ser humano tem o direito de deixar por escrito, } \\
\text { de manifestar para quando até mesmo ele não estiver em condições de verbalizar isso. " "A } \\
\text { gente tem essa faculdade, que é uma faculdade não é uma norma, você pode ou não fazer } \\
\text { isso. Então, a partir que essa faculdade não está contrariando a lei, eu acho positiva e válida" }\end{array}$ \\
\hline TULIPA & "Bom, eu acho que tem que ter ah...a vontade da pessoa tem que prevalecer." \\
\hline HORTÊNCIA & $\begin{array}{l}\text { "Olha, eu entendo que no mundo moderno, no momento, né, com o que nós estamos } \\
\text { vivendo, são salutares, são indispensáveis, né?!" }\end{array}$ \\
\hline
\end{tabular}

Tabela 2 - Resposta dos tabeliães quando questionados se havia algum modelo prévio para as Diretivas Antecipadas de Vontade, realizado em Porto Alegre em 2014. (Categoria Critérios de avaliação da parte)

\begin{tabular}{ll}
\hline TABELIÃES & RESPOSTAS \\
\hline Bromélia & "Modelo até temos"... "Tem que analisar caso a caso." \\
\hline Girassol & $\begin{array}{l}\text { "A gente se baseou em um formulário de um colega de São Paulo". "Não é uma escritura } \\
\text { padrão base, cada caso é um caso. " }\end{array}$ \\
\hline Orquídea & "Não, não tem modelo. Eu faço através de testamento. " \\
\hline Violeta & "Não. " \\
\hline Jasmim & "É uma entrevista. " "Eu transformo isso em texto e faço o testamento." \\
\hline Cravo & "Na época a gente fez um instrumento particular. Após este instrumento particular a gente \\
\hline Gérbera & acabou conversando com o colégio notarial e aí resolvemos fazer por instrumento público. " \\
\hline
\end{tabular}

Tabela 3 - Critérios exigidos para proceder com o registro de uma Diretiva Antecipada de Vontade, realizado em Porto Alegre em 2014. (Categoria Modelo para formalização da Diretiva Antecipada de Vontade)

\begin{tabular}{ll}
\hline TABELIÃES & RESPOSTAS \\
\hline Jasmim & $\begin{array}{l}\text { "Somente a análise da lucidez da pessoa que está procedendo. " "É uma entrevista com a } \\
\text { pessoa que deve procurar voluntariamente, não pode vir, de maneira nenhuma, acompanhada, } \\
\text { sugestionada. "É uma entrevista individual e a pessoa manifesta essa intenção, né?!" }\end{array}$ \\
\hline Tulipa & "Ah, a lucidez, né, da pessoa. A vontade realmente, né?! Em princípio, assim, se a pessoa está \\
& $\begin{array}{l}\text { lúcida, se é coerente, se é capaz. A capacidade dela para isso, né?! Se ela sabe realmente o } \\
\text { que que ela está fazendo e que isso, né, vai acarretar no futuro. E que ela saiba, também, que } \\
\text { isso é uma vontade, não quer dizer que, às vezes a pessoa acha que determinando assim a } \\
\text { familia vai fazer, os médicos vão fazer, é uma vontade. " "Se a pessoa é lúcida, coerente e } \\
\\
\text { capaz, né?!" }\end{array}$ \\
\hline Gérbera & "O tabelião tem três pilares sobre o ato jurídico que ele vai celebrar, tem que estar completo: \\
& agente capaz, objeto lícito, forma prevista ou não defesa em lei." "99\% eu avalio pessoalmente." \\
\hline Hortência & "Ah, os critérios são, em primeiro lugar a identificação da parte, a devida avaliação da \\
& capacidade da pessoa, a clara manifestação de vontade, inequívoca e clara, não é?!!" \\
\hline
\end{tabular}




\begin{tabular}{ll}
\hline Rosa & "Em primeiro lugar tem que ter os requisitos dentro do estabelecido pela legislação: devem \\
& ser maiores e capazes. Capazes, quando eu digo, é em respeito a capacidade civil. Então essa \\
& análise da capacidade civil quem faz é o tabelião. Que vai ter uma entrevista com o declarante \\
& para ver quais as disposições, quais as diretrizes que ele vai traças, né?!" \\
\hline Bromélia & "É um pouco subjetiva essa questão de critério. Não vejo, assim, um critério específico. A não \\
& ser algumas questões legais, fora isso não vejo nenhum problema." \\
\hline Cravo & "Para nós o único critério é a qualificação da pessoa e se ela está capaz ou não, né?! É a \\
& funça do tabelião. "
\end{tabular}

Tabela 4 - Avaliação da capacidade decisória por parte dos tabeliães, realizado em Porto Alegre em 2014. (Categoria Entrevista para avaliação da parte)

\begin{tabular}{ll}
\hline TABELIÃES & RESPOSTAS \\
\hline Rosa & $\begin{array}{l}\text { "Eu não sou médico, né?! Para dizer se a pessoa está em perfeito juízo, mas numa conversa } \\
\text { eu vou saber, né?!" }\end{array}$ \\
\hline Bromélia & $\begin{array}{l}\text { "Não há um critério específico, eu acho que tem que avaliar realmente a capacidade, é uma } \\
\text { conversa, conversando um pouquinho e tu já vai avaliando, vai analisando, até que ponto a } \\
\text { pessoa tem realmente capacidade. " }\end{array}$ \\
\hline Jasmim & "O critério é uma entrevista comigo. Se eu avaliar mal, ficou mal, mas isso eu garanto que não \\
\hline Orquídea & "O mesmo critério que é utilizado para testamento. Fazer uma entrevista e verificar." \\
\hline Cravo & $\begin{array}{l}\text { "A capacidade é através de um encaminhamento. A gente conversa com a parte e verifica a } \\
\text { capacidade dela, como qualquer outro instrumento que a gente faça aqui. " }\end{array}$ \\
\hline Tulipa & "É uma conversa, é no diálogo. " \\
\hline Hortência & $\begin{array}{l}\text { "Uma entrevista prévia. " "Se for uma pessoa idosa a gente tem o cuidado de ver se ela está } \\
\text { lúcida, não é? E se aquela é mesmo à vontade e, importante, se ela não está sendo coagida. " }\end{array}$ \\
\hline Gérbera & "Eu faço uma entrevista prévia só nós dois. " "Na conversa já tenho uma ideia da lucidez da \\
\hline
\end{tabular}

Tabela 5 - Relato dos tabeliães sobre a exigência, ou não, de atestado médico, realizado em Porto Alegre em 2014. (Categoria Atestado médico)

\begin{tabular}{ll}
\hline TABELIÃES & RESPOSTAS \\
\hline Rosa & $\begin{array}{l}\text { "Não, porque eu acho que no momento que eu exijo um atestado médico eu to duvidando } \\
\text { de alguma coisa." }\end{array}$ \\
\hline Bromélia & $\begin{array}{l}\text { "Eu não exijo atestado médico, a não ser em algumas excepcionalidades, só para a pessoa } \\
\text { antecipar ou reforçar aquilo que eu já estou dizendo, que a responsabilidade é toda minha. " }\end{array}$ \\
\hline Girassol & "Dependendo da idade a gente faz uma triagem, um questionário, e dependendo da idade a \\
& gente pede também um atestado médico, para verificar a capacidade da pessoa. " \\
\hline Orquídea & "Quando ultrapassar determinada idade ou houver alguma dúvida se valha de laudo \\
& neurológico ou psiquiátrico para auxílio da responsabilidade. Para garantia do cumprimento \\
\hline Lírio & "Em alguns casos se pede o atestado médico se está são ou não. Normalmente quando há \\
& diligências em hospitais. " \\
\hline
\end{tabular}




\begin{tabular}{ll}
\hline Tulipa & "Se for necessário a gente pede um atestado médico, né?! Fora da residência, aí sim a gente \\
& $\begin{array}{l}\text { pede o atestado, e em último caso, assim até, ah...quando surge alguma dúvida, né, porque } \\
\text { muitas vezes não é fácil atestar a lucidez, a capacidade. " }\end{array}$ \\
\hline Jasmim & "Atestado médico quando nós saímos daqui, em residências, hospitais, pessoas estão doentes, \\
& aí sim. Exijo e ainda assim eu converso com a pessoa, se eu não perceber segurança eu não \\
& faço." \\
\hline Cravo & "Não. Pela lei não é..não existe essa exigência. A gente não exige. A não ser que a pessoa \\
& tenha 90 anos, né?!" \\
\hline Gérbera & "Se eu tenho qualquer dúvida em relação a pessoa por idade, enfim, por vício de manifestação \\
& "Pe vontade cometido por idade, eu peço um atestado médico, de capacidade intelectual. " \\
& "Por idade, por volta dos 80 anos. " \\
\hline
\end{tabular}

\section{CONSIDERAÇÕES FINAIS}

A realização desta investigação mostrou que, embora nem todos os tabeliães da cidade de Porto Alegre tenham conhecimento da Resolução 1.995 do Conselho Federal de Medicina que trata das DAV, todos se mostraram abertos e favoráveis ao registro público deste ato de vontade priorizando o respeito a autonomia do indivíduo muito preconizada na Bioética. Porém, estes profissionais demonstraram muita preocupação com a condição de lucidez da pessoa que vai assinar o documento.

Verifica-se que é primordial que haja uma uniformização da forma e exigências para registro de uma Diretiva Antecipada de Vontade. Percebe-se que a sociedade urge por uma regulamentação legislativa quanto ao tema, dirimindo os conflitos existes no cotidiano sobre o modo de registro, local, consequências, prazos, dentre outros critérios ainda presentes quanto à temática analisada. Assim, poderá se exigir o conhecimento de todos os agentes que exercem função de ente público, para resguardar os direitos e auxiliar da melhor forma a população.

Apesar do respaldo que a fé pública confere a um documento registrado no cartório, se este documento não for do conhecimento de pessoas que possam fazer dele algo exequível, ele poderá nunca ocorrer na prática. A pessoa tem que ter certeza de que quem irá levar ao conhecimento de todos a sua vontade fará com que ela seja cumprida. Caso todos sejam contra, mesmo que exista um documento assinado em cartório, ele poderá não ser posto em prática. Por outro lado, temos a manifestação direta ao médico que terá baseado na ética médica, a obrigação de cumprir a vontade do paciente. No entanto, nem sempre a pessoa estará apta para manifestar sua vontade ao médico, pois o fato que deseja manifestar sua vontade pode ocorrer antes que venha a declará-la ao profissional.

Assim, seria mais benéfico tanto para quem quer ver sua vontade cumprida quanto para o resguardo e segurança médica, que a pessoa pudesse entregar o documento firmado pelo tabelião, que tem fé pública e se cercou de todos os meios legais para firmar tal documento, ao médico pois há casos em que a palavra do médico é posta à prova, motivo este que leva à indicação de que hajam testemunhas quando houver o registro em prontuário.

\section{REFERÊNCIAS}

1.Instituto Brasileiro de Geografia e Epidemiologia (IBGE). Censo 2010. Características da população e dos domicílios: resultados do universo. [Capturado 2016 Jun 14]. Disponível em: http://biblioteca.ibge.gov.br/visualizacao/periodicos/93/cd_2010_caracteristicas_ populacao_domicilios.pdf 
2. Instituto Brasileiro de Geografia e Epidemiologia (IBGE). Censo 2010. População de idosos no Brasil. Disponível em: < http://www. censo2010.ibge.gov.br/sinopse/index.php?uf=43\&dados=26>. Acesso em: 03 maios 2015.

3. Seidll EMF, Zannon CMLC. Qualidade de vida e saúde: aspectos conceituais e metodológicos Caderno de Saúde Pública, Rio de Janeiro, 20(2):580-588, mar- abr, 2004.

4. Conselho Federal de Medicina. Resolução no 1.995/2012. [Capturado 2016 Jun 14]. Disponível em: < http://www.portalmedico.org. br/resolucoes/CFM/2012/1995_2012.pdf>

5. Alves CA. Linguagem, Diretivas Antecipadas de Vontade e Testamento Vital: uma interface nacional e internacional. Revista Bioethikos. 2013; 7(3): 259-270.

6. Crippa A, Buonicore GP, Feijó AGS. Diretivas antecipadas de vontade e a responsabilidade civil do Médico. Revista da AMRGIS. 2013; 57(4): 344-348.

7. Lippmann E. Testamento vital: o direito à dignidade humana. São Paulo: Matrix; 2013.

8. Brasil. Constituição da República Federativa do Brasil. Promulgada em 5 de outubro de 1988. 25ed. atual. e ampl. São Paulo: Saraiva; 2000.

9. Neto Orlandi N. Atividade Notorial - noções. In: Dip R. Introdução ao direito notarial e registral. Porto Alegre: Sergio Antonio Fabris Editor; 2004.p. 10-26.

10. Vasconcelos JA, Cruz AAR. Direito Notorial: teoria e prática. São Paulo: editora Juarez de Oliveira; 2000.

11. Comessatto MS. A função notorial como forma de prevenção de litígios. Porto Alegre: Norton editor; 2002.

12. Ceneviva W. Lei dos notários e dos registradores comentada. São Paulo: Saraiva; 2010.

13. Bardin L. Análise de Conteúdo: revisada e ampliada. São Paulo: Edições 70; 2011.

14. Dadalto L. Testamento vital. Rio de Janeiro: Lumen Juris; 2013.

15. Vasconcelos JN, Cruz AAR. Direito Notarial: teoria e prática. São Paulo: Editora Juarez de Oliveira; 2000.

16. Machado AAM. A função notarial como forma de prevenção de litígios [Monografia]. Presidente Prudente (SP): Faculdades integradas "Antônio Eufrásio de Toledo" - Faculdade de direito de Presidente Prudente; 2008.

17. Nery Júnior N, Nery RMA. Código Civil Comentado. São Paulo: Editora Revista dos Tribunais; 2008.

18. Lôbo P. Direito Civil: Sucessões. São Paulo: Editora Saraiva; 2013. 